\title{
Multiscale comparison of air quality modeling for an ozone occurrence during the 1996 Paso Del Norte Ozone Campaign
}

\author{
D. Lu $^{1}$, R. S. Reddy ${ }^{1}$, R. Fitzgerald ${ }^{2}$, W. R. Stockwell ${ }^{3}$, \\ Q. L. Williams ${ }^{1} \&$ P. B. Tchounwou ${ }^{4}$ \\ ${ }^{I}$ Department of Physics, Atmospheric Science \& Geoscience, \\ Jackson State University, USA \\ ${ }^{2}$ Physics Department, University of Texas at El Paso, USA \\ ${ }^{3}$ Program of Atmospheric Sciences, Howard University, USA \\ ${ }^{4} \mathrm{NIH}-\mathrm{RCMI}$ Center for Environmental Health, \\ Jackson State University, USA
}

\begin{abstract}
An air quality modeling has been applied to investigate an ozone event occurring during the period of 1996 Paso del Norte Ozone Campaign. An examination of model sensitivity to horizontal grid resolutions has been performed. The modeling results show that grid resolution evidently influences the simulations of ozone formation, dispersion, transportation and structural distribution. The 36-, 12-, 4- and 1-km models captured the diurnal variation of surface ozone, but with a few hours lag for simulated peak ozone. The coarser the spatial resolution of the model, the more the peak ozone lag occurs. All models underpredicted the peak ozone concentration where the 1-km model produced the best while the 36$\mathrm{km}$ model yielded the worst. This study suggests that the problems of maximum ozone underprediction and minimum ozone overprediction can be mitigated by increasing the spatial resolution of the model. Compared to fine models, coarse models provided rather simple and smooth structures with many detailed and complex structures being lost. The frequency distribution analysis also revealed that the high ozone event occurring over the complex terrain area such as El Paso, TX can hardly be captured by using coarse spatial resolution models, and the high resolution model (i.e., grid spacing is no greater than $4-\mathrm{km}$ ) is necessary.
\end{abstract}


Keywords: air quality modeling, multiscale comparison, high ozone event, $C M A Q, S M O K E, W R F$.

\section{Introduction}

Ozone is formed from a series of chemical reactions among its precursors. The major precursors of ozone are oxides of nitrogen $\left(\mathrm{NOX}=\mathrm{NO}+\mathrm{NO}_{2}\right)$ and volatile organic compounds (VOCs). These precursors are emitted primarily from fossil fuel combustion and automobile sources and are subsequently oxidized to produce ozone through a complex series of interactions involving various chemical and physical processes [1]. Because of the complexity of ozone formation it is difficult to predict ozone episodes and impossible to understand its mechanism solely by direct experimental studies and field observations. Air quality modeling, however, provides a good alternative to study the physical and chemical mechanism of ozone formation due to model capabilities which provide a high temporal and spatial resolution study for a wide variety of pollutants. Most air quality models have adopted the three-dimensional Eulerian grid modeling framework which represents reasonable physical realism and predicts concentrations of the species throughout the entire model domain. When grid-based air quality models are used, the selection of grid cell size becomes important because the characteristics of species are regarded as uniform in each grid cell and chemical species are mainly denoted by concentration (i.e., mass per volume). Using coarse grids would cause the model to resolve emission strengths that are too low, especially in major source areas [1].

Additionally, the subgrid processes that regulate species transformations are assumed to be uniform in each grid cell, and certain characteristics of subgrid processes and their interactions may be lost as the size of the model grid cell increases. The U.S. Environmental Protection Agency (EPA) has recommended that the air quality modeling in support of the state implementation plan (SIP) may benefit from increased grid resolution [2]. An increased grid resolution model provides a more detailed and accurate representation of key factors such as complex terrain features, emission sources and urban characteristics. Jang et al. [1] found that, while the average transport of non-reactive species does not show sensitivity to grid resolution, reactive pollutants are sensitive. This suggests a nonlinear relationship between chemistry and horizontal grid size. Some studies have shown that increasing grid resolution does not always give better performance due to the challenge of the complexity in chemistry and meteorology and their nonlinear interactions and responses to grid size [3-5]. More studies and further analyses for the sensitivity of model predictions to horizontal grid resolutions are needed. The purpose of this study is to determine what spatial resolution is needed to successfully capture a high ozone event with a sufficient accuracy of intensity and detailed structure. 


\section{Case selection and observational data}

The case, August 131996 ozone episode, was selected from a major field study, the Paso del Norte Ozone study, which was conducted during the summer of 1996 for the purpose of providing sufficient data to support photochemical ozone air quality. The campaign was conducted from July to September of 1996. During this period, a local intensive observation network of air quality and meteorological monitoring sites was operated and contained a sounding site and 20 surface meteorological stations in El Paso, Ciudad Juarez and its surrounding communities [6]. Data from routine network monitoring provided hourly surface observations of chemistry species and meteorological parameters including temperature, relative humidity, wind speed, wind direction, ozone, nitric oxide (NO), the sum of nitric oxide and nitrogen dioxide (NOX), carbon monoxide (CO), and particulate matter (PM) [6, 7]. During the campaign period, 13 August 1996 was the only day which exceeded a 1-h NAAQS (National Ambient Air Quality Standard) of $0.12 \mathrm{ppm}$ in El Paso/Juarez area [7].

\section{Description of modeling system, input data and numerical design}

\subsection{Model system}

In our previous publication [8], we provided a detailed description of air quality model system that we used. There are three major components in this system: a meteorology model, a chemistry and transport processor, and an emission model. The meteorological model used is the Weather Research and Forecasting (WRF) [9], version 3.0. WRF is a next-generation mesoscale weather forecasting system designed to serve both operational and research needs. It is a limited-area, nonhydrostatic, primitive-equation mode with multiple options for various physical schemes. The Community Multiscale Air Quality Model (CMAQ) version 4.6 [10] has been used in this study as the chmical transport model. CMAQ is a comprehensive, three-dimensional, multiscale, Eulerian-based, atmospheric chemistry, transport and deposition model for multiple air pollutants including tropospheric ozone, acid deposition, particulate matter, visibility and air toxins. CMAQ has been served as a flexible and comprehensive modeling tool in various applications such as urban and regional air quality evaluations, formulating state implementation plans for non-attainment areas, and investigating atmospheric processes [11]. The emission inventory model used in this study is the Sparse Matrix Operator Kernel Emissions (SMOKE) Modeling System developed by Carolina Environmental Program at the University of North Carolina at Chapel Hill [12]. The SMOKE was used to convert the sourcelevel emissions (county total emissions) reported on a yearly basis to spatially resolved, hourly emissions, with detailed speciation information. SMOKE can 
generate the speciated, gridded emission inventory inputs for various air quality models, including CMAQ. SMOKE is able to process the point, area, biogenic, and mobile emission sources: point source emissions are gridded according to the physical location of emitting facilities; area and mobile source emissions are gridded according to the spatial allocation factors; biogenic emissions are calculated using Biogenic Emission Inventory System Version (BEIS) version 3.13 along with meteorological data such as surface solar irradiation and temperature. The version of SMOKE2.3 was used in this study.

\subsection{Input data}

The data incorporated into the WRF model as initialization and lateral boundary conditions are obtained from NCEP/NCAR Reanalysis with a 6 hour interval. This is the global dataset in the format of grib with the resolution of $2.5 \times 2.5$ degree. The emission inventory data used in this study are EPA's NEI99 (final version 2). The inventoried emissions in NEI99 include nitrogen oxides (NOx), sulfur dioxide (SO2), volatile organic compounds (VOCs), carbon monoxide (CO), ammonia (NH3), and particulate matter (PM) for point, area, non-road and on-road mobile emissions. Since the modeling domain includes both US and Mexico, the latest released Mexico emission dataset (Mexico NEI99. http:/www.epa.gov/ttn/chief/net/mexico.html), which include six northern border states of Mexico, has also been obtained as the supplementation for NEI99. All emission species were adjusted by running the SMOKE model from the year of 1999 to 1996 .

\subsection{Design of numerical simulations}

As addressed in $\mathrm{Lu}$ et al. [8], the WRF model was run over a one-way nested modeling domain centered at the location of El Paso $(31.70 \mathrm{~N}, 106.40 \mathrm{~W})$ with the spatial resolution of 36-, 12-, 4- and 1-km for the outer, two middle and inner domains (Fig. 1). The use of high spatial resolution simulation such as $1-\mathrm{km}$ was expected to resolve the unique weather phenomena occurring over the complex area like El Paso [6]. This is because mountainous topography produces regional circulation resulting in wind in the mountains and valleys which consequentlyaffects the local pollutant transportation and dispersion. We used 35 sigma vertical levels in WRF with 15 layers within the planetary boundary layer (PBL) (less than $1500 \mathrm{~m}$ ) where the lowest sigma level is at the height of $12 \mathrm{~m}$. This way helps resolve the emission and chemical reactions of pollutants occur within PBL. For WRF model simulation, the analysis nudging scheme, Four Dimensional Data Assimilation (FDDA) [13], was applied during the first 6 hour simulation in all domains in order to improve meteorological parameters forecasted qualities. 


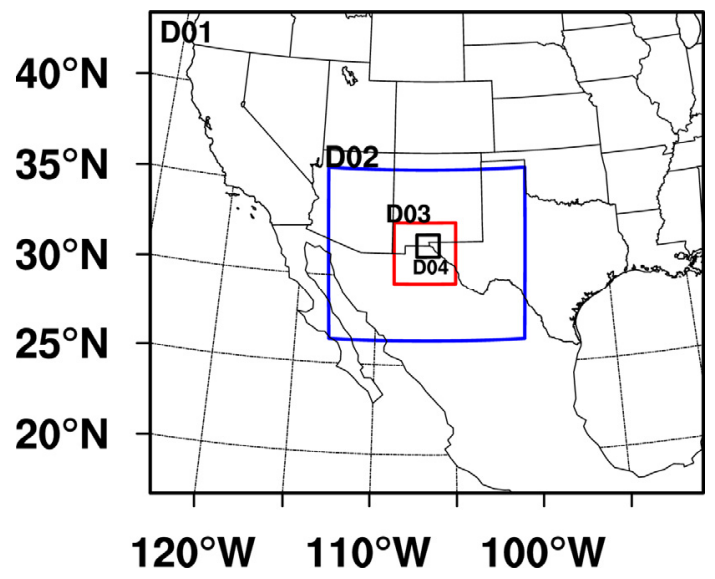

Figure 1: $\quad$ Nested domains used for WRF, SMOKE and CMAQ models. D01, D02, D03 and D04 are the outer, two middle and fine domains with the grid distances of 36-, 12-, 4- and 1-km respectively. The windows used by SMOKE and CMAQ are the maximum input of meteorological windows from WRF.

\section{Results and discussions}

\subsection{Temporal evolution}

One observational station, the site of Downtown El Paso, was selected to examine model performance in temporal variation of ground ozone concentration. Fig. 2 shows hourly surface ozone concentration comparisons between observations and model simulations at 1-, 4-, 12- and 36-km resolutions, respectively. It is found that all models provide a clear diurnal variation of surface ozone concentration. The maximum ozone appeared during the daytime and the minimum ozone occurred in the nighttime. For all models, the occurrences of peak ozone were noted to have a few hours lag between the simulations and the observation. The observed peak ozone was around 10:00 MST August 131996 while simulated peak ozone occurred around 13:00 MST from the 1-km model, 12:00 MST from the 4-km model, 15:00 MST from the $12-\mathrm{km}$ model and 16:00 MST from the 36-km model. This suggests that the coarser the model spatial resolution, the more the lag of peak ozone occurs. In accordance with the peak value of surface ozone, the 1-km model yielded the best result with a reasonable agreement between simulation and observation being observed. For example, the peak value of $101 \mathrm{ppb}$ was simulated with the 1-km model, $87 \mathrm{ppb}$ with 4-km, $67 \mathrm{ppb}$ with 12-km and $49 \mathrm{ppb}$ with 36-km models while the observed value was $134 \mathrm{ppb}$ [14]. All models underestimated the surface peak ozone concentration at this station. The $1-\mathrm{km}$ model predicted $75 \%$ of the observed peak ozone concentration, $4-\mathrm{km}$ model of $65 \%, 12-\mathrm{km}$ model of $50 \%$, and $36-\mathrm{km}$ model of $37 \%$. An evident overprediction of ozone 
concentration occurring during nighttime was noted at each of the 12- and 36-km models while two fine resolution models (1- and 4-km) provided the comparable minimum ozone concentrations compared to the observations. The possible contribution for simulated ozone errors in coarse domains may originate from the simulation errors of surface temperature, wind speed or humidity, as well as from the uncertainties of emission distribution and intensity. Since all models run with the same physical and chemical processes, the spatial resolution is clearly the key factor producing model errors. For the grid-based model such as CMAQ, grid size is important because the characteristics of species are treated uniformly in each grid cell and chemical species are denoted by concentration instead of by mass itself [1]. If the grid cell size is relatively large compared to the spatial distribution of source areas, the intense emission sources could be artificially smeared throughout the entire grid cell. Consequently, coarse grid models tend to produce emission strengths that are too low when compared to physical measurements, especially in those major emission source regions. Because the processes that regulate species transformations are assumed to be uniform in each grid cell, certain characteristics of subgrid processes and their interactions may also be lost as the size of the model grid cell increases. Due to the nonlinear effect of ozone chemistry, an averaged treatment of subgrid processes in a large grid cell may not adequately represent the subgrid interactions of ozone, its precursors and their important processes. Therefore, the surface ozone concentration turns out to be underestimated.

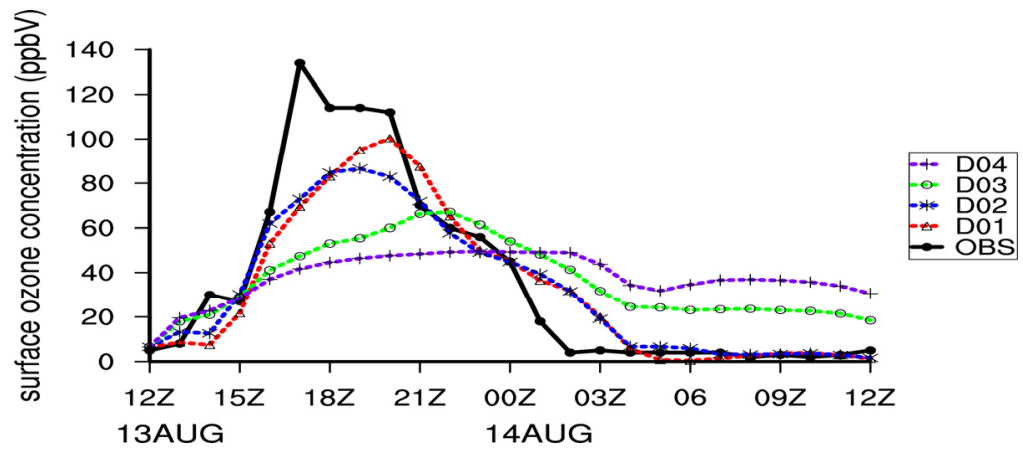

Figure 2: Hourly surface ozone concentration comparison between models at various spatial resolutions (1-, 4-, 12- and 36-km) and observation at the location of Downtown El Paso during the period from 12:00 UTC August 13 to 12:00 UTC August 14, 1996.

\subsection{Spatial distribution}

The model spatial resolution significantly influences the spatial pattern and central intensity of surface ozone concentration [1]. Fig. 3 shows the simulated surface ozone concentration at 20:00 UTC (13:00 MST) August 13 1996. Two coarser resolution models (36- and $12-\mathrm{km})$ produced the evident underestimates at most parts of the domain. The surface ozone centers are located at those areas 
that are discernible at the major cities and their downwind areas (Fig. 3(a) and (b)). The central strengths at those major emission source areas are obviously enhanced as the spatial resolution increases. Compared to two coarse models, the higher resolution models (4- and $1-\mathrm{km}$ ) provided much more detailed and complex structures of the surface ozone simulations. Regarding the El Paso area, although all models underpredicted the peak surface ozone concentration, higher resolution models significantly reduced the problem of underestimation. It is seen that maximum surface ozone concentrations at the time of 13:00 MST August 131996 in El Paso area are $80 \mathrm{ppb}$ in 4-km model (Fig. 3(c)) and 110 ppb in 1-km model (Fig. 3(d)). From an observational report [14], the average surface ozone concentration at El Paso / Juarez area at that time was around 114 ppb. The 1-km model of the CMAQ approximately captured the peak surface ozone while the $4-\mathrm{km}$ model reproduced $72 \%$, the $12-\mathrm{km}$ model reproduced $63 \%$, and the $36-\mathrm{km}$ model reproduced $44 \%$. Close examining the surface ozone

(a)

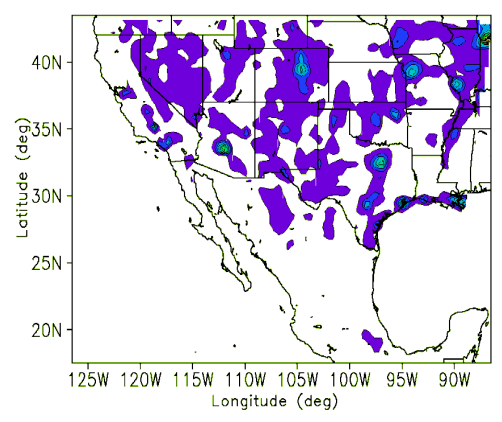

(c)

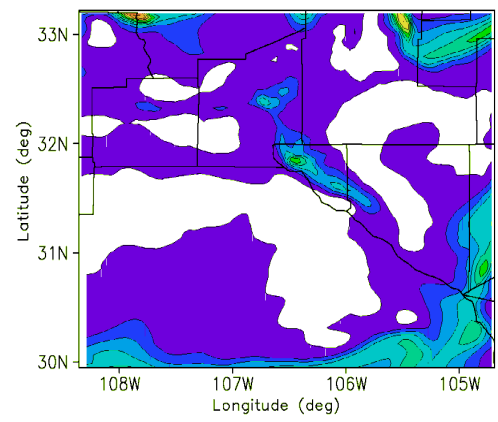

(b)
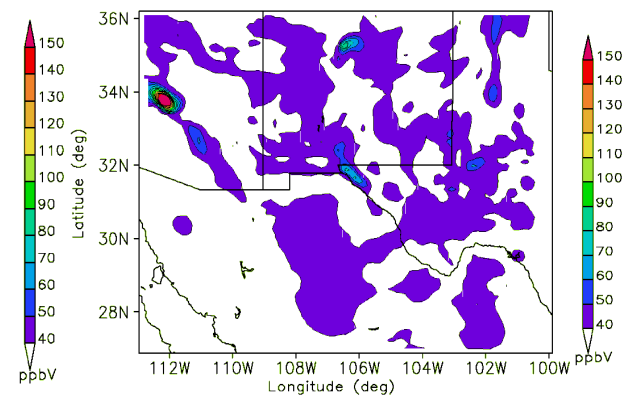

(d)

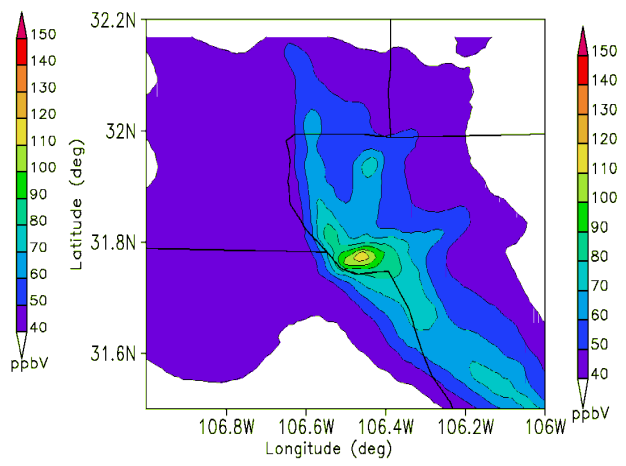

Figure 3: $\quad$ Surface ozone concentration (ppbV) at 13:00 MST August 131996 from CMAQ modeling with grid spacing of $(a) 36-$, , b ) 12-, (c) 4and $(d) 1-\mathrm{km}$, respectively. 
concentration distributions in the same region as the 1-km domain coverage from $36-, 12-$ and 4-km domains reveals that the coarse model $(36-\mathrm{km})$ provided surface ozone distributions that were rather simple and smooth. The interested region was labeled with two lines of $40 \mathrm{ppb}$ and $50 \mathrm{ppb}$ contours (not shown). Many locally associated features were not captured. From 12- and 4-km domains it is found that (not shown) the higher the spatial resolution, the more detailed structures the model produced.

In addition, all models successfully captured the spatial evolution of surface ozone concentration (not shown). Simulations showed that, in the morning, high ozone concentration areas were located along Rio Grande River Valley. The distribution of surface ozone featured a spatial pattern of southeast-to-northwest direction. At the time of local noon, the center of surface ozone concentration moved northwestward and ended-up at the southwestern part of El Paso. Then, the surface ozone area moved westward along the US-Mexico border. This special pattern from model simulation is consistent with the local observations. Roberts et al. [14] reported that that an ozone cloud formed over the urban areas of Juarez and El Paso and flowed towards the northwest by the prevailing southeasterly winds. This unique track is mainly associated with the local topography distribution [7], especially under the ozone favorable condition where a calm weather dominates. The main geographical features of El Paso/Ciudad Juarez area are the Franklin Mountains, which run north-to-south and end abruptly just north of downtown El Paso; the Juarez Mountains, which lie to the west of Ciudad Juarez; and the Rio Grande River valley that divides the Franklin and Juarez Mountains and runs generally northwest-to-southeast through the domain. During summer, light northwesterly winds are prevailing under the condition of large-scale high pressure systems dominating in this area. Surface ozone will be advected through the prevailing winds northwestward. However, the Franklin Mountains stop further movement of the winds and turn them westerly, resulting in the spatial pattern of simulated surface ozone distribution.

\subsection{Frequency distribution}

To quantitatively describe the underestimation of surface ozone concentration from all models, the frequency distribution of hourly ozone concentration versus various concentrations at 13:00 MST August 13 1996 has been established (Fig. 4). The frequency is defined as the percentile fraction of the grid cells occupied by a given concentration threshold. It was calculated by considering all grid cells in each model. The range of surface ozone concentration corresponding to the peak frequency shifted to the higher ozone concentrations as model spatial resolution increases from 36- to $4-\mathrm{km}$. The peak frequency occurred at the range of surface ozone concentration between $30-40 \mathrm{ppb}$ for the 36-km model, 40-50 $\mathrm{ppb}$ for the $12-\mathrm{km}$ model, and around $50 \mathrm{ppb}$ for the $4-\mathrm{km}$ model. This indicates that the decrease in grid cell size will increase the number of places that exhibit higher surface ozone concentrations. However, the $1-\mathrm{km}$ model simulation exhibited an exception in that the peak frequency of simulated surface ozone is located at the place of the concentration of $40 \mathrm{ppb}$. Closer inspection of 
frequency distribution at high concentration thresholds (not shown) reveals that for the thresholds higher than $60 \mathrm{ppb}$, the frequencies of model outputs from two coarse grid resolutions, 36- and 12-km, were all zeros. In contrast, two fine grid resolution models, $4-$ and $1-\mathrm{km}$, provided the frequencies that were at the range from $1 \%$ to $5 \%$ at these high thresholds.

Figure 5 shows frequency distributions from all models where the frequency of each model was calculated by only considering those grid cells located within the coverage of the 1-km domain. With the focus being on such a small area, the

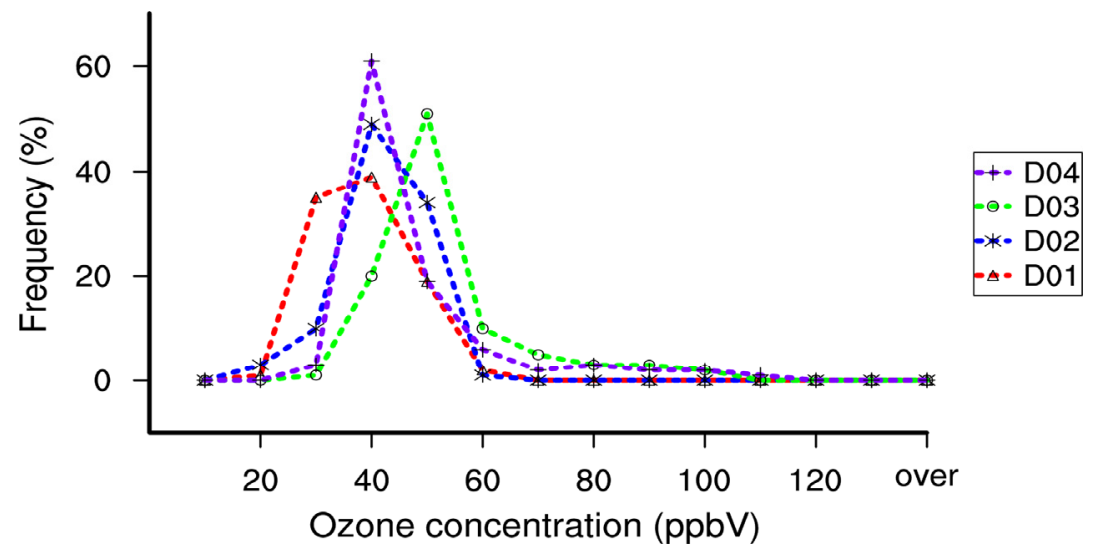

Figure 4: Comparison of the frequency distributions of hourly surface ozone concentration at 13:00 MST August 131996 from model outputs at 36-km (D01), 12-km (D02), 04km (D03) and 1-km (D04). There are 14 thresholds from $0-130 \mathrm{ppb}$.

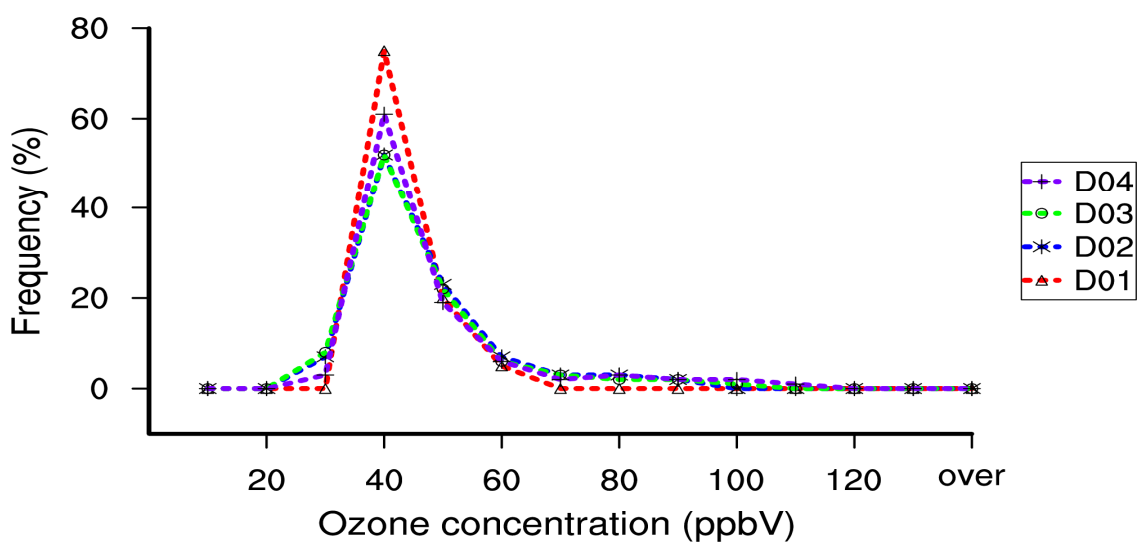

Figure 5: $\quad$ Same as Fig. 4 but with the frequency of each model calculated by only considering those grid cells located within the coverage of the $1-\mathrm{km}$ domain. 
threshold shifting among different spatial resolution models shown in Fig. 4 has not been found. The peak frequencies of all models occurred in the range of 40 $50 \mathrm{ppb}$ for surface ozone concentration. The $36-\mathrm{km}$ model failed to capture the high ozone event because the frequency was approximately zero at threshold greater than $70 \mathrm{ppb}$. In contrast, two fine grid resolution models, 1- and 4-km, predicted some grids in this region with the surface ozone concentration exceeding $100 \mathrm{ppb}$. This mitigation of the surface ozone underestimation problem could be attributable to the capability of the high resolution models to resolve the fine information for the mountainous topography such as El Paso/Ciudad Juarez area.

\section{Summary and conclusions}

A modeling study was performed for a high ozone occurrence during the 1996 Paso del Norte Ozone campaign by incorporating meteorological model (WRF), emission model (SMOKE) and air quality chemical reactive and transport model (CMAQ) to investigate the sensitivity of model spatial resolution to surface ozone concentration. The results showed that grid resolution significantly affects the simulation of ozone formation, dispersion, transportation and structural distribution. Although all models captured the diurnal variation of surface ozone, a few hours lag of peak ozone concentration occurred for each model. The coarser the spatial resolution of model, the larger the lag of peak ozone. It is found that all models underpredicted the peak ozone concentration. The $1-\mathrm{km}$ model produced the best result while the $36-\mathrm{km}$ model yielded the worst. In addition, the coarser models (36- and 12-km) tended to overpredict the minimum ozone concentration in the nighttime. The problems of maximum ozone underprediction and minimum ozone overprediction are related to the spatial resolution model used. The minimum ozone overestimation may be attributed to the excessive predicting on the mixing process during nighttime. Excessive vertical mixing will result in upper-level ozone. The application of the high resolution model tends to suppress the excessive mixing process. Although previous studies have shown limited benefit with a higher grid resolution in ozone simulation and found that higher grid resolution simulation does not always enhance model performance, our studies revealed that increasing the horizontal spatial resolution is one way to reduce the problem of maximum ozone underprediction and minimum ozone overprediction. All models captured the evolution of the high ozone event. But the coarse resolution application (36and $12-\mathrm{km}$ ) provided rather coarse textured spatial fields compared to the fine models (1- and 4-km). Many detailed and complex structures were lost from the coarser models. In contrast, the $1-\mathrm{km}$ model provided an areal surface ozone concentration that is in very good agreement with that observed in the sense of central strength. The analysis of the frequency distribution revealed that the range of surface ozone concentration corresponding to the peak frequency shifted to the higher ozone concentration thresholds as the model spatial resolution increased from 36- to $4-\mathrm{km}$. But further increases in spatial resolution to $1-\mathrm{km}$ did not draw the similar conclusion. The $36-$ and $12-\mathrm{km}$ models failed to provide 
the frequency that is greater than zero at the thresholds above $70 \mathrm{ppb}$. This suggests that the high ozone event can hardly be captured by using coarse spatial resolution models. Therefore, to successfully capture the high ozone occurrence, such as the event occurring on 13 August 1996, with the acceptable accuracy of central strength and sufficiently detailed structural distribution, a high resolution model (i.e., grid spacing is no greater than $4-\mathrm{km}$ ) is necessary.

\section{Acknowledgements}

This research was supported by the NOAA Educational Partnership Program with Minority Serving Institutions (EPP/MSI) under grant \# NA06OAR4810172 through the NOAA Center for Atmospheric Sciences (NCAS). The authors want to express their gratitude to Dr. Paul Roberts, from Sonoma Tech, for providing them with important data collected during the 1996 ozone campaign performed in El Paso, TX. The support of NIH RCMI grant \# G12RR013459-12 is also acknowledged.

\section{References}

[1] Jang, J.C., Jeffries, H.E., Byun, D., Pleim, J.E, Sensitivity of ozone to model grid resolution: I. Application of high-resolution regional acid deposition model. Atmos. Environ. 29, pp. 3085-3100, 1995.

[2] US EPA. Guidance on the Use of Model and Other Analyses for Demonstrate Attainment of Air Quality Goals for Ozone, PM2.5, and Regional Haze, EPA-454/B-07-002, April, 2007.

[3] Zhang, Y., Liu, P., Pun, B., Seigneur, C., A comprehensive performance evaluation of MM5-CMAQ for the Summer 1999 southern oxidants study episode, Part-I. Evaluation protocols, database and meteorological predictions. Atmos. Environ., 40, pp. 4825-4838, 2006.

[4] Zhang, Y., Liu, P., Queen, A., Misenis, C., Pun, B., Seigneur, C., Wu, S.Y., A comprehensive performance evaluation of MM5-CMAQ for the Summer 1999 southern oxidants study episode, Part-II. Gas and aerosol predictions. Atmos. Environ., 40, pp. 4839-4855, 2006.

[5] Wu, S.-Y., Krishnanb,S., Zhang, Y., Aneja, V., Modeling atmospheric transport and fate of ammonia in North Carolina-Part I: Evaluation of meteorological and chemical predictions. Atmos. Environ., 42, pp. 34193436, 2008.

[6] Brown, M.J., Muller, C., Wang, W., Costigan, K., Meteorological simulations of boundary-layer structure during the 1996 Paso del Norte Ozone Study. Sci Total Environ., 276, pp. 111-133, 2001.

[7] MacDonald, C.P., Roberts, P.T., Main, H.H., Dye, T.S., Coe, D.L., Yarbrough J., The 1996 Paso del Norte Ozone Study: analysis of meteorological and air quality data that influence local ozone concentrations. Sci. Total Environ., 276, pp. 93-109, 2001.

[8] Lu, D., Reddy, R.S., Fitzgerald, R., Stockwell, W.R., Williams, Q.L., Tchounwou, P.B., Sensitivity modeling study for an ozone occurrence 
during the 1996 Paso del Norte Ozone Campaign. Int. J. Eviron. Res. Public Health, 5, pp. 181-203, 2008.

[9] Skamarock, W.C., Klemp, J.B., Dudhia, J., Prototypes for the WRF (Weather Research and Forecasting) model. In Proceedings of Ninth Conference on Mesoscale Processes, Fort Lauderdale, FL, USA. 2001.

[10] Byun, D.W., Ching, J.K.S., Science Algorithms of the EPA Models-3 Community Multiscale Air Quality Model (CMAQ) Modeling System. EPA/600/R-99/030, US Environmental Protection Agency, 1999, Office of Research and Development, Washington DC, USA. 20460.

[11] Lin, C.J., Ho, T.C., Chu, H., Yang, H., Mojica, M.J., Krishnarajanagar, N., Chandru, S., Krishnarajanagar, N., Chiou, P., Hopper, J.R., Sensitivity analysis of ground-level ozone concentration to emission changes in two urban regions of southeast Texas. J. of Environ Manag., 75, pp. 315-323, 2005.

[12] Houyoux, M.R., Vukovich, J.M., Coats, C.J., Emission inventory development and processing for the Seasonal Model for Regional Air Quality (SMRAQ) project. J. Geophys. Res. 105, pp. 9079-9090, 2001.

[13] Stauffer, D. R., Seaman, N.L., Multiscale four-dimensional data assimilation. J. Appl. Meteor, 33, pp. 416-434, 1994.

[14] Roberts, P.T, MacDonald, C.P., Main, H.H., Dye, T.S., Coe, D.L., Haste, T.L., Analysis of meteorological and air quality data for the 1996 Paso del Norte Ozone Study. Final report prepared for the U.S. Environmental Protection Agency, Region 6 Dallas, TX, by Sonoma Technology Inc. Santa Rosa, CA under subcontract to Science Applications International Corporation McLean, VA, 1997. 